\title{
Quality of Life in Alopecia Areata: A Sample of Tunisian Patients
}

\author{
Jawaher Masmoudi, ${ }_{1}^{1}$ Rim Sellami, ${ }^{1}$ Uta Ouali, ${ }^{1}$ Leila Mnif, ${ }^{1}$ Ines Feki, ${ }^{1}$ Mariam Amouri, ${ }^{2}$ \\ Hamida Turki, ${ }^{2}$ and Abdellaziz Jaoua ${ }^{1}$
}

${ }^{1}$ Department of Psychiatry A, Hédi Chaker University Hospital, Sfax, Tunisia

${ }^{2}$ Department of Dermatology, Hédi Chaker University Hospital, Sfax, Tunisia

Correspondence should be addressed to Jawaher Masmoudi; amirsoussi@yahoo.fr

Received 12 June 2013; Accepted 4 July 2013

Academic Editor: Masutaka Furue

Copyright (C) 2013 Jawaher Masmoudi et al. This is an open access article distributed under the Creative Commons Attribution License, which permits unrestricted use, distribution, and reproduction in any medium, provided the original work is properly cited.

\begin{abstract}
Background. Alopecia areata (AA) has a significant impact on the quality of life and social interaction of those suffering from it. Our aim was to assess the impact of AA on the quality of life. Methods. Fifty patients diagnosed with AA seen in the Department of Dermatology of Hedi Chaker University Hospital, between March 2010 and July 2010, were included. Quality of life was measured by SF 36; severity of AA was measured by SALT. Results. Eighty percent had patchy alopecia with less than $50 \%$ involvement, $12 \%$ had patchy alopecia with $50-99 \%$ involvement, and $8 \%$ had alopecia totalis. Compared with the general population, AA patients presented a significantly altered quality of life, found in the global score and in five subscores of the SF-36: mental health, role emotional, social functioning, vitality, and general health. Gender, age, marital status, and severity of alopecia areata had a significant influence on patients' quality of life. Conclusions. This study indicates that patients with AA experience a poor quality of life, which impacts their overall health. We suggest screening for psychiatric distress. Studies of interventions such as counseling, psychoeducation, and psychotherapeutic interventions to reduce the impact of the disease may be warranted.
\end{abstract}

\section{Introduction}

Alopecia areata $(\mathrm{AA})$ is a common disease with an incidence of $2-3 \%$ among the dermatoses and $0.1 \%$ in the population at large [1]. This disorder occurs in both sexes, at all ages [2], and is characterized by the sudden appearance of areas of hair loss on the scalp and other hair-bearing areas. Various factors, including immunologic and endocrine abnormalities [3], genetic factors [4], infections [5], and psychological/psychiatric disturbances, have been claimed to play a role in its etiopathogenesis [6]. Hence, it is suspected to be an autoimmune disease having a genetic predisposition and being influenced by environmental and ethnic factors. Epidemiological studies of AA are available from the USA, Japan, and European countries [7-9]. However, there is a paucity of data from Arab countries, with especially one published study from Kuwait done in the pediatric age group [10].

Hair loss significantly impacts an individual's self image, and studies indicate that patients with both clinically apparent and clinically imperceptible hair loss may have significantly decreased quality of life $[11,12]$. Quality of life is defined as the subjective perception of the impact on the health status and on the physical, psychological, and social functioning and well-being of the patients [13]. Although AA is a medically benign condition, it can affect patients' quality of life [2]. Indeed, AA can have psychosocial complications, including depression, low self-esteem, altered self-image, and less frequent and enjoyable social engagements [14-16]. To assess the severity of AA, quality of life seems to be a more relevant criterion than clinical evaluation such as AA extension because the perception of patients may differ significantly from those of their health-care providers [13].

The aim of our study was to examine the impact of AA on the different dimensions of quality of life and to determine factors related to an altered quality of life.

\section{Methods}

All new patients diagnosed with AA seen in the Department of Dermatology of Hedi Chaker University Hospital between March 2010 and July 2010 were included in the study. 
Informed consent was obtained from all subjects enrolled. The diagnosis of AA was made by a qualified dermatologist on a clinical basis. Sociodemographic and clinical data including age, sex, family history of AA, site of onset, and associated diseases were recorded for all patients. Included patients underwent full clinical examination to determine the number and extension of the sites affected by AA and the severity of the disease.

The severity of hair loss was assessed by measuring the percentage of the alopecic area on the scalp. Patients with AA were evaluated using Severity of Alopecia Tool (SALT) [17]. The SALT score is computed by measuring the percentage of hair loss in each of 4 areas of the scalp ( $40 \%$ vertex, $18 \%$ right profile, $18 \%$ left profile, $24 \%$ posterior) and adding the total to achieve a composite score.

Patients were divided into four groups according to disease severity: S1-S2: hair loss below 50\%; S3-S4: hair loss of 50-99\%; S5: total scalp hair loss.

Following examination, a health survey in its short form (SF36) was administered to all included patients. The SF36 health survey is a widely used generic, 36-item, selfreported health status questionnaire assessing eight domains of health status (1) physical functioning; (2) role physical; (3) bodily pain; (4) mental health; (5) role emotional; (6) social functioning; (7) vitality; (8) general health. A score from 0 to 100 is calculated for each subscale, with higher scores indicating better quality of life. It has been translated into Arabic and validated but not yet published [18]. Physical functioning domain addresses physical activities associated with daily life, such as bathing, walking, or carrying groceries. Role-physical domain assesses how physical health affects work. Bodily pain domain measures pain severity and how it interferes with daily activities. Mental health domain assesses the subject's mood, specifically focusing on feelings of sadness and anxiety. Role emotional domain addresses how the subject's emotional state has influenced work and other daily activities. Social functioning domain measures how much emotional or physical problems have interfered with usual social activities. Vitality domain assesses how energetic or tired the subject feels. Finally, general health domain describes how the patient perceives health status. The findings of the SF-36 were compared with those of a control group consisting of healthy volunteers, with no known chronic skin disease, of similar age, sex, and level of education. The group of patients and 50 controls did not show significant differences concerning age $(P=1.000)$, educational level $(P=0.802)$, and gender $(P=0.987)$. The control group had not any organic or psychiatric disease.

The mean total score of each domain of SF36 in patients with AA was compared with the mean score of the control group by $t$-test. The $t$-test comparisons for each subscale were evaluated with statistical significance designated as $P$ less than 0.05 . We also examined the relationship between different domains of quality of life and several independent variables, including marital status, gender, illness severity, and age. Associations with quality of life were tested using $t$ tests and one-way ANOVAs with post hoc LSD multiple comparison tests and correlations (Spearman and Pearson). The use of parametric versus nonparametric tests was
TABLE 1: Quality of life comparisons between AA patients and controls.

\begin{tabular}{lccc}
\hline Dimensions of SF-36 & $\begin{array}{c}\text { Patients } \\
\mathrm{M} \pm \mathrm{ET}\end{array}$ & $\begin{array}{c}\text { Controls } \\
\mathrm{M} \pm \mathrm{ET}\end{array}$ & $P$ \\
\hline D1: physical functioning & $93.10 \pm 12.45$ & $88.30 \pm 17.57$ & 0.118 \\
D2: role physical & $95.50 \pm 10.93$ & $90.20 \pm 16.31$ & 0.059 \\
D3: bodily pain & $95.40 \pm 12.48$ & $89.80 \pm 16.22$ & 0.056 \\
D4: mental health & $63.64 \pm 16.61$ & $77.14 \pm 11.03$ & $<0.001$ \\
D5: role emotional & $33.33 \pm 36.26$ & $83.06 \pm 24.40$ & $<0.001$ \\
D6: social functioning & $54.60 \pm 33.75$ & $82.20 \pm 18.56$ & $<0.001$ \\
D7: vitality & $62.40 \pm 21.19$ & $77.00 \pm 14.70$ & $<0.001$ \\
D8: general health & $58.17 \pm 17.06$ & $71.62 \pm 13.71$ & $<0.001$ \\
Mean score & $68.95 \pm 13.10$ & $80.52 \pm 9.14$ & $<0.001$ \\
\hline
\end{tabular}

dependent on the scale of measurement and distribution of the results.

\section{Results}

Fifty patients were included in the study. Their mean age was 32.92 years $(\mathrm{SD}=11.81)$, having a minimum of 18 years and a maximum of 60 years. There were $48 \%$ males and $52 \%$ females with a male to female ratio of 0.92 . As to the level of education, $18 \%$ had elementary school education, $40 \%$ had secondary school education, and $42 \%$ had higher education level.

Fifty-two percent of patients were single, $46 \%$ were married, and $2 \%$ of them were divorced. As to occupation, most worked (52\%) some were retired (2\%), and whereas the others were studying (24\%) or unemployed (22\%).

At the time of first presentation, $80 \%$ had patchy alopecia with less than 50\% involvement (S1-S2), 12\% had patchy alopecia with 50-99\% involvement (S3-S4), and $8 \%$ had alopecia totalis.

Patient's quality of life, demonstrated by SF-36 scores, ranged from 38.54 to 92.7 with a mean $68.95( \pm 13.10)$. Compared with the general population (Table 1), AA patients presented a significantly altered quality of life, found in the global score and in five subscores of the SF-36: mental health (D4), role emotional (D5), social functioning (D6), vitality (D7), and general health (D8) (Table 1).

Females scored lower on the SF 36 than males: this gender difference was significant for the global score $(P=0.007)$ and three subscores: physical functioning $(P=0.028)$, general health $(P=0.012)$, and role emotional $(P=0.018)$.

The correlation of Pearson indicated a significantly altered mental health domain in younger patients $(r=0.336$, $P=0.017)$.

Furthermore, we observed a significant difference in the scores of the mental health subscale (D4) between married and unmarried patients $(P=0.050)$ : unmarried patients scored lower than married patients.

In our study, we found a relationship between poorer quality of life and severity of AA. This relationship was significant in the SF-36 subscale of mental health and social functioning: patients with $51 \%$ to $75 \%$ of hair loss (S3) 
TABLE 2: Correlation between quality of life and severity.

\begin{tabular}{lcccccr}
\hline \multirow{2}{*}{ Dimensions of SF-36 } & S1 & S2 & S3 & S5 & \multicolumn{2}{c}{ ANOVA } \\
& $\mathrm{M} \pm \mathrm{ET}$ & $\mathrm{M} \pm \mathrm{ET}$ & $\mathrm{M} \pm \mathrm{ET}$ & $\mathrm{M} \pm \mathrm{ET}$ & $F$ & $P$ \\
\hline D1: physical functioning & $93.87 \pm 10.3$ & $86.66 \pm 21.06$ & $99.16 \pm 2.04$ & $92.5 \pm 8.66$ & 1.347 & 0.271 \\
D2: role physical & $94.35 \pm 10.62$ & 100 & $91.66 \pm 20.41$ & 100 & 1.099 & 0.359 \\
D3: bodily pain & $92.58 \pm 15.26$ & 100 & 100 & 100 & 1.422 & 0.249 \\
D4: mental health & $66.54 \pm 13.93$ & $67 \pm 15.65$ & $56.66 \pm 20.61$ & $44 \pm 21.66$ & 2.978 & 0.041 \\
D5: role emotional & $40.85 \pm 38.2$ & $18.51 \pm 33.79$ & $33.33 \pm 29.81$ & $8.33 \pm 16.66$ & 1.641 & 0.193 \\
D6: social functioning & $64.83 \pm 29.19$ & $48.88 \pm 30.18$ & $21.66 \pm 32.5$ & $37.5 \pm 43.49$ & 3.856 & 0.015 \\
D7: vitality & $61.45 \pm 19.67$ & $59.62 \pm 12.07$ & $61.66 \pm 32.5$ & $72.5 \pm 5$ & 0.316 & 0.814 \\
D8: general health & $59.21 \pm 16.65$ & $66.37 \pm 13.33$ & $52.2 \pm 26.35$ & $55.83 \pm 17.92$ & 0.315 & 0.815 \\
Mean score & $71.22 \pm 13.33$ & $80.52 \pm 9.14$ & $64.54 \pm 14.45$ & $63.82 \pm 12.09$ & 0.850 & 0.474 \\
\hline
\end{tabular}

showed significantly lower scores on the social functioning subscale compared to those with hair loss less than 25\% (S1) (Table 2). Patients with $100 \%$ extent of hair loss (S5) showed significantly lower scores on the mental health subscale compared to those with $51 \%$ to $75 \%$ of hair loss (S3). Severity of AA was related to lower scores in the mental health domain $(r=-0.379 ; P=0.007)$ as well as lower scores in the social functioning domain $(r=-0.365 ; P=0.009)$.

\section{Discussion}

In our study, we observed a slight female preponderance for AA. (M/F: 0.92). This is in agreement with other studies [1921]. However, the results of the literature are disparate. Thus, for some authors, AA affects men and women with the same proportions $[2,22,23]$.

We have found that included patients had a lower quality of life compared to the control group. Dimensions of the SF36 referring to psychological and social components were particularly affected. Indeed, several studies underline that the experience of AA is psychologically damaging, causes intense emotional suffering, and leads to personal, social, and work related problems [24]. Our results are in line with authors' findings that report quality of life to be seriously impaired, mainly, by altering self-perception and self-esteem $[25,26]$.

This may be because of the special importance of hair in appearance [27]. Hair is a distinctive and valued facial characteristic, and the way it is styled helps to define the individual's self-concept and identity. Through hair loss, the ability to manipulate and improve appearance may become uncertain and out of one's control [28, 29]. In fact, AA might make the individual focus on the bold patches, which leads to even greater distress.

On the other hand, the alteration of psychological and relational dimensions of patients' quality of life could be dependent on the regular recurrence and unpredictable severity of AA, leaving a feeling of incomprehension and vulnerability [30]. Moreover, the unpredictable hair loss and the fact that there is currently no effective remedy could cause particular anxiety related to uncertainty about the patient's future appearance [31].
The disease not only has a severe psychological impact but also causes a marked disturbance in the social life of the patients forcing them to avoid social meetings, change their hair style, and alter the type of clothing. In Tunisia, where Islamic customs prevail, women try to cover their hair. This observation was found in Kuwaiti and Egyptian studies [32].

Our results showed that women have a more significantly altered quality of life than men. The dimensions of general health and role emotional were particularly affected. In consistency with our findings, several other studies have reported a particularly impaired quality of life for women [11, 33]. Femininity, sexuality, and personality are symbolically linked to a woman's hair, more so than for a man [34]. Indeed, a women's self-esteem is often more dependent on physical appearance compared to men [29], and hair strongly influences whether or not an individual is seen as physically attractive [35]. In line with social stereotypes, men were more likely to express concern over work interference, whereas women were more concerned with the social impact of such a visible condition. There is an important link between hair and identity, especially for women, even in Arab Muslim culture. Hair loss may be seen in terms of abnormality and as a failure to conform to the norms of physical appearance in society, which has the potential to set people apart in their own estimation and in the estimation of others. So, AA in women significantly affects self-image, and psychosocial factors often negatively impact patients' quality of life [33, 36-38].

In our study, we found that a patient's age was correlated to the SF 36 dimension of mental health: the younger the patient is, the more his mental health is negatively affected by AA. Furthermore, our study showed that unmarried patients had significantly altered scores in the dimension of mental health compared to married patients. Our results are in accordance with two recent studies $[32,38]$ which found that the impact of AA on the quality of life was more pronounced within younger age groups. Indeed, hair loss would entail more concern among those most vulnerable such as younger patients. These results denote that unestablished social life in younger and unmarried patients makes them worry about their future resulting in more psychological distress.

In our study, we found a relationship between the severity of AA and poorer quality of life (Figure 1). 


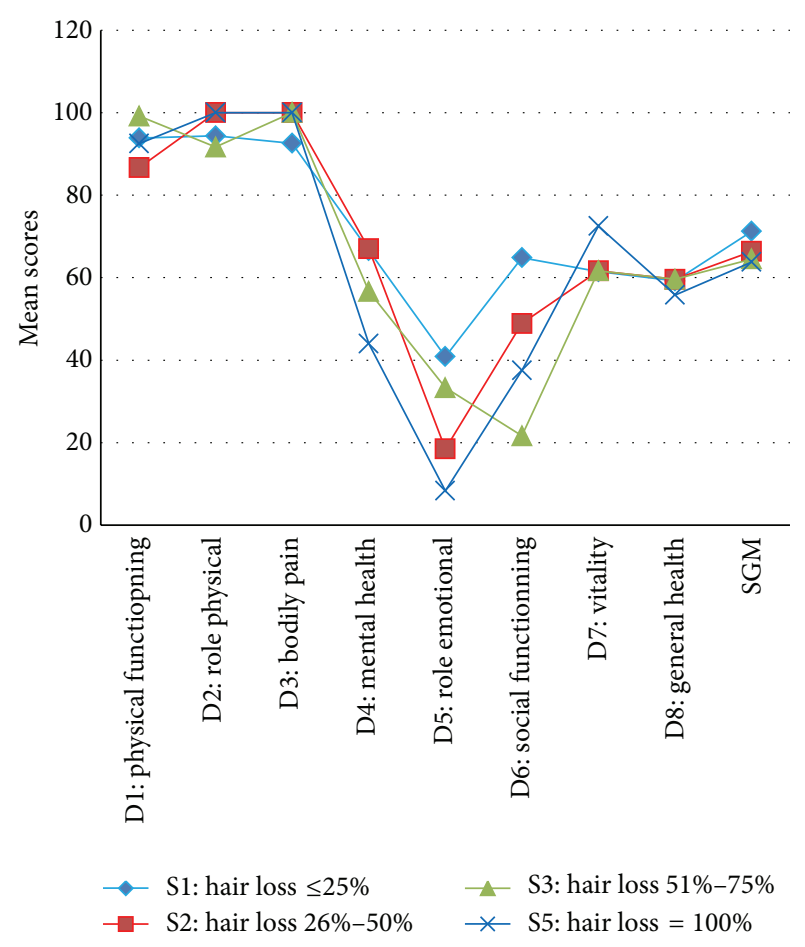

FIGURE 1: Mean scores SF-36 depending on the severity (SALT).

The domains referring to psychological and social components were particularly affected in patients with severe forms of AA. Indeed, given the psychological importance of hair, patients with severe forms of AA might find it more difficult to cope with their hair loss. According to Tan et al. [19], patients who presented limited AA appeared to be less affected than those who had an extensive AA. This shows that if AA is more severe, its impact on quality of life is more important. However, the relationship between disease severity and impaired quality of life has not been confirmed by all studies [39]. A study by Krueger et al. [40] revealed that AA areas in particularly visible locations had a more severe impact on quality of life than an area of the same size in a less visible location. Interestingly, a study by Reid et al. [41] showed that patients' quality of life was strongly correlated with the patient's perception of hair loss rather than with the clinical severity of hair loss. Generally, patients tend to perceive their hair loss as worse than clinical assessment, but patients and physicians seem to have synchronous scales of severity.

This lack of parallelism between clinical severity, patients' perception of hair loss, and psychological impact might be partly responsible for the frequent underestimation of psychological distress [42].

There are some limitations to our study that should be taken into consideration. First, the sample size was relatively small. Furthermore, it could have been interesting to assess the quality of life with a scale specially designed for dermatologic patients. However, to our knowledge, there is no such instrument translated in Arabic language so far.

\section{Conclusion}

This study indicates that patients with AA experience a poor quality of life, which profoundly impacts their overall health and sense of well-being. Also, when examining a patient who is at high risk for poor quality of life, it would be reasonable to screen for psychiatric distress. Those with mild impairments should be encouraged to discuss their concerns at clinic visits or in a support-group setting. Moreover, the efficacy of any treatment must also consider the improvement in quality of life and not just see the percentage of hair regrowth. Studies of interventions such as counseling, psychoeducation, and psychotherapeutic interventions to reduce the impact of the disease may be warranted.

\section{Conflict of Interests}

The authors have no potential conflict of interests.

\section{References}

[1] E. Healy and S. Rogers, "PUVA treatment for alopecia areatadoes it work? a retrospective review of 102 cases," British Journal of Dermatology, vol. 129, no. 1, pp. 42-44, 1993.

[2] S. A. Muller and R. K. Winkelmann, "Alopecia areata: an evaluation of 736 patients," Archives of Dermatology, vol. 88, pp. 290-297, 1963.

[3] V. H. Price and B. W. Colombe, "Heritable factors distinguish two types of alopecia areata," Dermatologic Clinics, vol. 14, no. 4, pp. 679-689, 1996.

[4] J. Shapiro, "Alopecia areata: update on therapy," Dermatologic Clinics, vol. 11, no. 1, pp. 35-46, 1993.

[5] R. B. Skinner Jr., W. H. Light, G. F. Bale, E. W. Rosenberg, and C. Leonardi, "Alopecia areata and presence of cytomegalovirus DNA," Journal of the American Medical Association, vol. 273, no. 18, pp. 1419-1420, 1995.

[6] E. Arca and Z. Kurumlu, "Etiopathogenesis, clinical features, and diagnosis in alopecia areata," Dermatose, vol. 2, pp. 83-89, 2003.

[7] D. A. De Berker, A. G. Messenger, and R. D. Sinclair, "Disorders of hair," in Rook's Textbook of Dermatology, T. Burns, S. Breathnach, N. Cox, and C. Griffiths, Eds., vol. 4, pp. 36-63, Blackwell Scientific Publications, Oxford, UK, 2004.

[8] L. A. Drake, R. I. Ceilley, R. L. Cornelison et al., "Guidelines of care for alopecia areata," Journal of the American Academy of Dermatology, vol. 26, no. 2, pp. 247-250, 1992.

[9] V. H. Price, "Alopecia areata: clinical aspects," Journal of Investigative Dermatology, vol. 96, no. 5, p. 68, 1991.

[10] A. Nanda, A. S. Al-Fouzan, and F. Al-Hasawi, "Alopecia areata in children: a clinical profile," Pediatric Dermatology, vol. 19, no. 6, pp. 482-485, 2002.

[11] N. Hunt and S. McHale, "The psychological impact of alopecia," British Medical Journal, vol. 331, no. 7522, pp. 951-953, 2005.

[12] F. Poot, "Psychological consequences of chronic hair diseases," Revue Medicale de Bruxelles, vol. 25, no. 4, pp. 286-288, 2004.

[13] G. Kiebert, S. V. Sorensen, D. Revicki et al., "Atopic dermatitis is associated with a decrement in health-related quality of life," International Journal of Dermatology, vol. 41, no. 3, pp. 151-158, 2002. 
[14] H. O. Beard, "Social and psychological implications of alopecia areata," Journal of the American Academy of Dermatology, vol. 14, no. 4, pp. 697-700, 1986.

[15] A. Firooz, M. R. Firoozabadi, B. Ghazisaidi, and Y. Dowlati, "Concepts of patients with alopecia areata about their disease," BMC Dermatology, vol. 5, 2005.

[16] M. A. Gupta and A. K. Gupta, "Depression and suicidal ideation in dermatology patients with acne, alopecia areata, atopic dermatitis and psoriasis," British Journal of Dermatology, vol. 139, no. 5, pp. 846-850, 1998.

[17] E. A. Olsen, M. K. Hordinsky, V. H. Price et al., "Alopecia areata investigational assessment guidelines-part II," Journal of the American Academy of Dermatology, vol. 51, no. 3, pp. 440-447, 2004.

[18] C. Allouche, L'indice SF36 de la qualité de vie: traduction en langue arabe et étude des qualités métrologiques. Doctoral dissertation in medicine. Sfax 2007. Number 2553.

[19] E. Tan, Y.-K. Tay, C.-L. Goh, and Y. C. Giam, "The pattern and profile of alopecia areata in Singapore-a study of 219 Asians," International Journal of Dermatology, vol. 41, no. 11, pp. 748-753, 2002.

[20] A. Kavak, N. Yeşildal, A. H. Parlak et al., "Alopecia areata in Turkey: demographic and clinical features," Journal of the European Academy of Dermatology and Venereology, vol. 22, no. 8, pp. 977-981, 2008.

[21] K. P. Kyriakis, K. Paltatzidou, E. Kosma, E. Sofouri, A. Tadros, and E. Rachioti, "Alopecia areata prevalence by gender and age," Journal of the European Academy of Dermatology and Venereology, vol. 23, no. 5, pp. 572-573, 2009.

[22] S. Madani and J. Shapiro, "Alopecia areata update," Journal of the American Academy of Dermatology, vol. 42, no. 4, pp. 549-570, 2000.

[23] D. Wasserman, D. A. Guzman-Sanchez, K. Scott, and A. Mcmichael, "Alopecia areata," International Journal of Dermatology, vol. 46, no. 2, pp. 121-131, 2007.

[24] N. Hunt and S. McHale, "Reported experiences of persons with alopecia areata," Journal of Loss and Trauma, vol. 10, no. 1, pp. 33-50, 2005.

[25] M. Dubois, K. Baumstarck-Barrau, C. Gaudy-Marqueste et al., "Quality of life in alopecia areata: a study of 60 cases," Journal of Investigative Dermatology, vol. 130, no. 12, pp. 2830-2833, 2010.

[26] A. T. Gulec, N. Tanriverdi, D. Dürü et al., "The role of psychological factors in alopecia areata and the impact of the disease on the quality of life," International Journal of Dermatology, vol. 43, no. 5, pp. 352-356, 2004.

[27] A. Firooz, M. R. Firoozabadi, B. Ghazisaidi, and Y. Dowlati, "Concepts of patients with alopecia areata about their disease," BMC Dermatology, vol. 5, 2005.

[28] T. F. Cash, "The psychosocial consequences of androgenetic alopecia: a review of the research literature," British Journal of Dermatology, vol. 141, no. 3, pp. 398-405, 1999.

[29] T. F. Cash, "The psychology of hair loss and its implications for patient care," Clinics in Dermatology, vol. 19, no. 2, pp. 161-166, 2001.

[30] Assouly P. Pelade. Encycl Med Chir, Dermatologie. 2006, 37400-C-10.

[31] L. Papadopoulos and R. Bor, Psychological Approaches to dermatology, BPS Books/in lived experience of AA, Leicester, UK, 1999.

[32] N. Al-Mutairi and O. N. Eldin, "Clinical profile and impact on quality of life: seven years experience with patients of alopecia areata," Indian Journal of Dermatology, Venereology and Leprology, vol. 77, no. 4, pp. 489-493, 2011.

[33] D. Williamson, M. Gonzalez, and A. Y. Finlay, "The effect of hair loss in quality of life," Journal of the European Academy of Dermatology and Venereology, vol. 15, no. 2, pp. 137-139, 2001.

[34] N. Wolf, The Beauty Myth, William Morrow and Company, New York, NY, USA, 1991.

[35] G. L. Patzer, "Psychologic and sociologic dimensions of hair: an aspect of the physical attractiveness phenomenon," Clinics in Dermatology, vol. 6, no. 4, pp. 93-101, 1988.

[36] F. M. Camacho and M. Garcia-Hernandez, "Psychological features of androgenetic alopecia," Journal of the European Academy of Dermatology and Venereology, vol. 16, no. 5, pp. 476480, 2002.

[37] J. Y. M. Koo, W. V. R. Shellow, C. P. Hallman, and J. E. Edwards, "Alopecia areata and increased prevalence of psychiatric disorders," International Journal of Dermatology, vol. 33, no. 12, pp. 849-850, 1994.

[38] T. Cartwright, N. Endean, and A. Porter, "Illness perceptions, coping and quality of life in patients with alopecia," British Journal of Dermatology, vol. 160, no. 5, pp. 1034-1039, 2009.

[39] M. A. Gupta and A. K. Gupta, "Psychiatric and psychological co-morbidity in patients with dermatologic disorders: epidemiology and management," American Journal of Clinical Dermatology, vol. 4, no. 12, pp. 833-842, 2003.

[40] G. G. Krueger, S. R. Feldman, C. Camisa et al., "Two considerations for patients with psoriasis and their clinicians: what defines mild, moderate, and severe psoriasis? what constitutes a clinically significant improvement when treating psoriasis?" Journal of the American Academy of Dermatology, vol. 43, no. 2 I, pp. 281-285, 2000.

[41] E. E. Reid, A. C. Haley, J. H. Borovicka et al., "Clinical severity does not reliably predict quality of life in women with alopecia areata, telogen effluvium, or androgenic alopecia," Journal of the American Academy of Dermatology, vol. 66, no. 3, pp. e97-e102, 2012.

[42] S. G. Consoli, M. Chastaing, and L. Misery, "Psychiatrie et dermatologie," Encycl Med Chir. 2010, 98-874-A-10. 


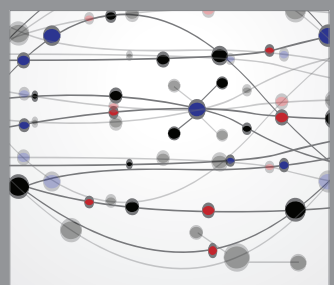

The Scientific World Journal
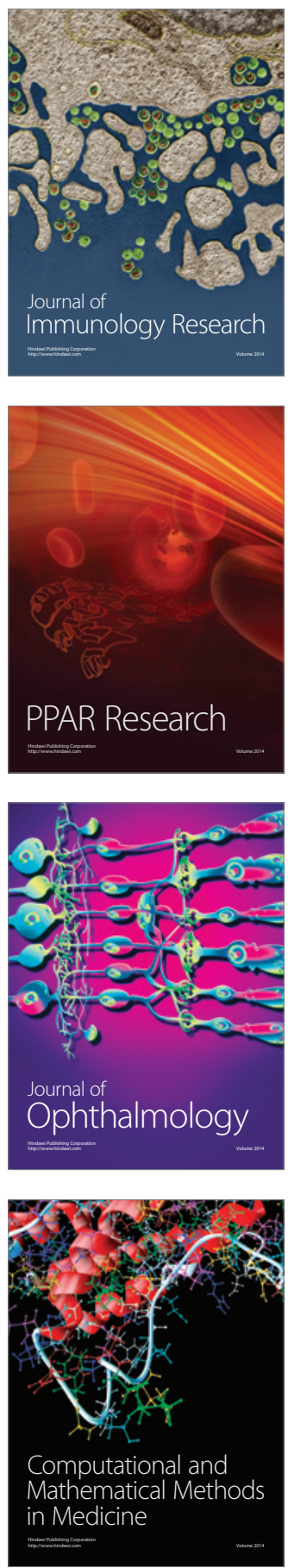

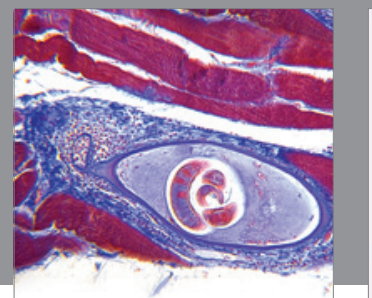

Gastroenterology

Research and Practice
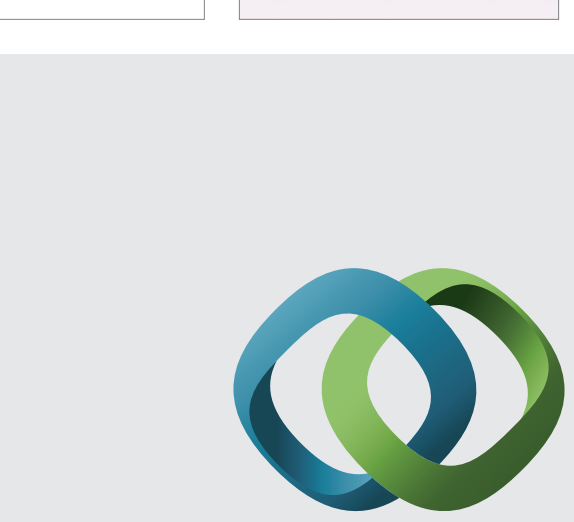

\section{Hindawi}

Submit your manuscripts at

http://www.hindawi.com
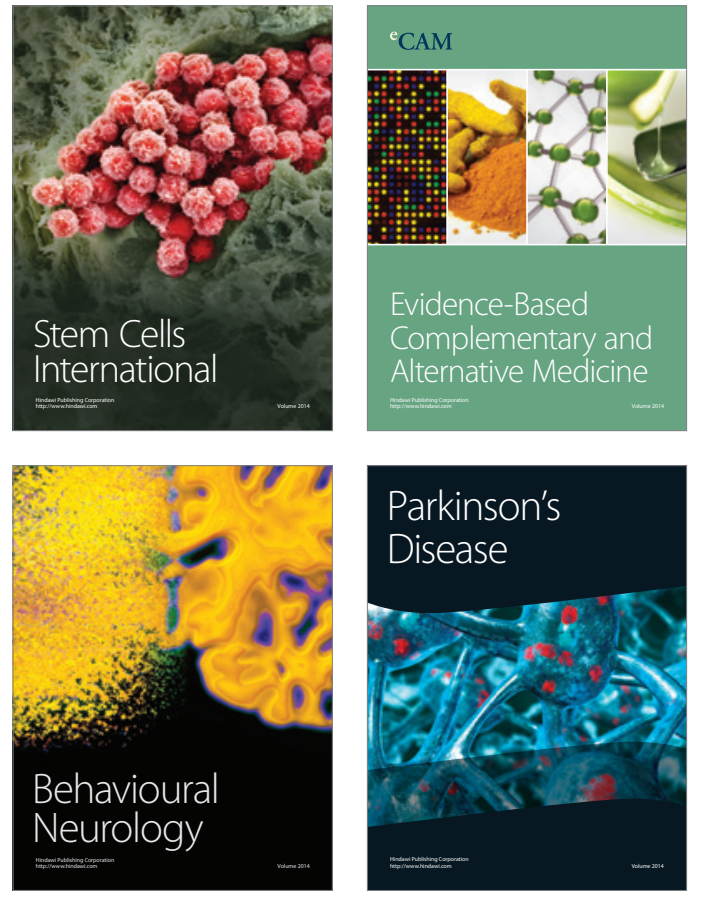
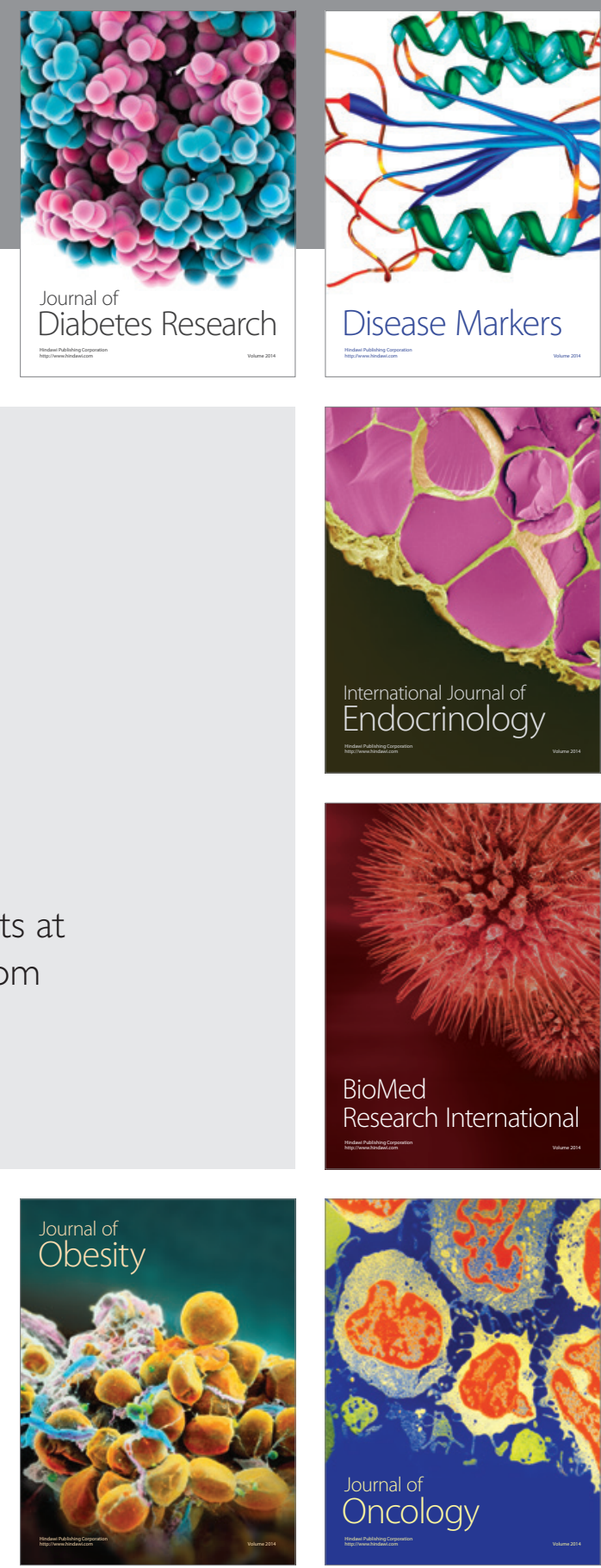

Disease Markers
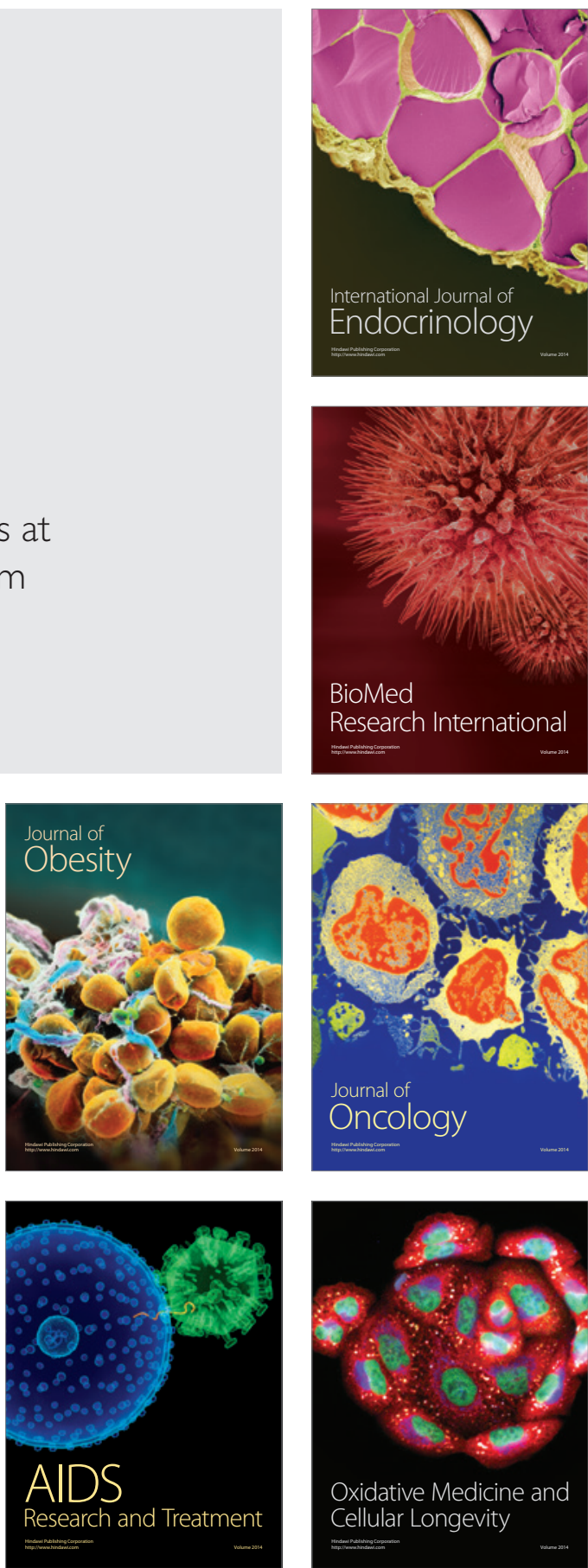